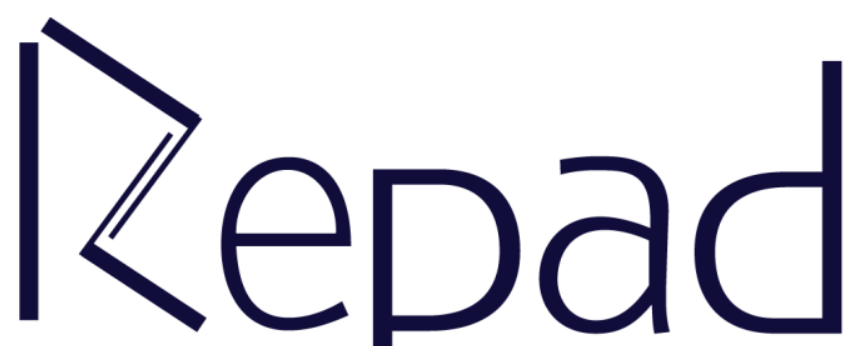

v. 5 , n. 2, Maio-Agosto/2021

Revista Estudos e

Pesquisas em Administração

(cC) (i) This work is licensed under a Creative Commons Attribution 4.0 International License 


\title{
EDUCAÇÃO FINANCEIRA: Influência dos fatores demográficos e socioeconômicos na atitude e comportamento financeiro de estudantes do ensino médio
}

\author{
Beatriz Ribeiro Xavier \\ beatriz.rx@hotmail.com \\ https://orcid.org/0000-0002-1793-7161 \\ http://lattes.cnpq.br/1551328890191261 \\ Universidade Federal de Mato Grosso do Sul, Campus de Três Lagoas \\ Andradina, São Paulo, Brasil \\ Tamires Sousa Araújo \\ tamires.sousa@ufms.br \\ https://orcid.org/0000-0002-0926-151X \\ http://lattes.cnpq.br/7499540310685652 \\ Universidade Federal de Mato Grosso do Sul, Campus de Três Lagoas \\ Três Lagoas, Mato Grosso do Sul, Brasil \\ Sirlei Tonello Tisott \\ sirlei.tisott@ufms.br \\ http://orcid.org/0000-0001-9432-234X \\ http://lattes.cnpq.br/1604397401494604 \\ Universidade Federal de Mato Grosso do Sul, Campus de Três Lagoas \\ Três Lagoas, Mato Grosso do Sul, Brasil

Cleston Alexandre dos Santos
cleston.alexandre@ @otmail.com
https://orcid.org/0000-0001-7014-6644
http://lattes.cnpq.br/7454296010892827
Universidade Federal de Mato Grosso do Sul, Campus de Três Lagoas
Três Lagoas, Mato Grosso do Sul, Brasil

\section{Resumo}

Este artigo procurou analisar a influência dos fatores demográficos e socioeconômicos na atitude e comportamento financeiro de estudantes do ensino médio nas regiões do interior de Mato Grosso do Sul e São Paulo, onde até então não havia estudos desta natureza. A amostra desta pesquisa foi composta por discentes de instituições de ensino públicas do interior dos estados de São Paulo e de Mato Grosso do Sul. A metodologia utilizada foi a de pesquisa descritiva, com abordagem quantitativa feita por meio de um levantamento. Para isso, aplicou-se um questionário adaptado de Potrich, Vieira e Ceretta (2013) e Potrich, Vieira e Kirch (2015). Diante dos resultados, constatou-se que a educação financeira é pouco expressiva no cotidiano desses estudantes. Foi possível identificar pelos fatores demográficos e socioeconômicos analisados que gênero e renda não exercem influência sobre a educação financeira dos estudantes, mas que a escolaridade dos pais exerce uma influência significativa. Os achados revelam uma educação financeira que não pode ser considerada boa, sendo a atitude financeira razoável e o comportamento financeiro insuficiente. $\mathrm{Na}$ Atitude Financeira os respondentes têm ciência de que precisam estabelecer metas e que isso impactará nos 
investimentos futuros, mas quanto ao Comportamento Financeiro, na prática, não utilizam um orçamento para estabelecer metas e controlar os gastos. Com este artigo, pretende-se estimular instituições públicas e privadas a elaborar programas que contribuam com a educação financeira de seus alunos, formando, assim, cidadãos capacitados para gerenciar suas finanças pessoais de forma satisfatória, evitando o endividamento precoce.

Palavras-chave: Alfabetização financeira. Comportamento financeiro. Finanças.

\title{
FINANCIAL EDUCATION: influence of demographic and socioeconomic factors on the attitude and financial behavior of high school students
}

\begin{abstract}
This paper seeked to analyze the influence of demographic and socioeconomic factors in the attitude and financial behavior of high school students in the countryside of the States of Mato Grosso do Sul and São Paulo, places in which there weren't studies of this nature. The sample of this research was composed of students from public institutions from the countryside of the states of São Paulo and Mato Grosso do Sul. The descriptive research was used as methodology with a quantitative approach. The data were collected using a version of the questionnaire by Potrich, Vieira and Ceretta (2013) and Potrich, Vieira and Kirch (2015). The results indicate that the financial education is not very expressive in the daily lives of these students. It was possible to identify that demographic and socioeconomic factors of observed students demonstrate that gender and income don't influence on their financial education, however the parental education does. The findings reveal that their financial education isn't good, their financial attitude is reasonable and financial behavior is insufficient. Considering Financial Attitude, the respondents are aware they need to set goals which will impact their future investments, but in practice, they don't observe their budgets to set the goals and control their spending. This paper intends to encourage public and private institutions to elaborate programs to contribute to their students' financial education, thus, forming capable citizens to manage their own personal finances in a satisfactory way, avoiding early indebtedness.
\end{abstract}

Keywords: Financial Literacy. Financial behavior. finances.

Submetido: 04/01/2021

Revisões Requeridas: 03/04/2021

Aceito: $24 / 07 / 2021$

Publicado: 31/08/2021

\section{INTRODUÇÃO}

O comportamento atual do brasileiro em relação ao consumo é reflexo da forma como as gerações anteriores lidavam com as finanças, período no qual "a economia brasileira antes do plano real era instável e não se sabia nem qual o valor do salário do próximo mês devido às altas inflações" (OLIVEIRA et al., 2016, p. 3). 
Consequentemente, a população era impulsionada a consumir devido à incerteza da modificação frequente dos preços. Vieira, Bataglia e Sereia $(2011$, p. 62) afirmam que "neste ambiente econômico, o indivíduo é levado às decisões de curto prazo e à falta de planejamento".

Após este período, com a estabilização da moeda e a diminuição da inflação, tornou-se possível um maior poder aquisitivo por meio da oferta de créditos e financiamentos mais extensos (VIEIRA; BATAGLIA; SEREIA, 2011). Todavia, sem a devida administração destes recursos, há um fomento direto ao consumismo. Carvalho e Scholz (2018, p. 106) afirmam que por conta dessa oferta de crédito e financiamentos mais extensos "as pessoas têm dificuldades de enxergar as taxas e juros embutidos nos produtos pelas empresas, pois estes juros muitas vezes se encontram de forma oculta para justamente camuflar o real valor dos produtos ou serviços ofertados, principalmente daqueles oferecidos a prazo".

Gerações mais atuais ainda podem possuir um comportamento similar ao da geração anterior. Isso é causado por fatores adversos, como o da constante competição entre organizações para obterem a atenção e fidelidade dos consumidores. Muitas empresas utilizam aplicativos e websites que projetam técnicas de marketing como ambientação, promoções e cupons para equiparar-se as influências que engajam o consumo em lojas físicas (COSTA; LARN, 2003), o que aumenta a aquisição de celulares, televisões, carros, computadores e viagens aéreas.

Wisniewski (2011) afirmam que hábitos de consumo são constantemente associados com bem-estar pela mídia, direcionando ao endividamento. Em uma pesquisa feita pela Confederação Nacional do Comércio de Bens, Serviços e Turismo (CNC, 2020), um total de 66,6\% dos brasileiros estão endividados e cerca de $10,6 \%$ não terá condições de pagar suas dívidas. Dentre os diversos tipos de dívidas, o principal $(76,7 \%)$ é o cartão de crédito (CNC, 2020).

Nesse cenário, o consumidor se torna vulnerável por dificilmente possuir o hábito de poupar dinheiro para casos de emergências ou eventuais crises financeiras. Notoriamente, a crise brasileira de 2014 mostrou ser a segunda pior recessão desde 1990, com um encolhimento de 3,8\% do Produto Interno Bruto (PIB) em 2015 e 3,6\% em 2016 em proporção a 2015 (PESQUISA NACIONAL POR AMOSTRA DE DOMICÍLIOS - PNAD, 2017). Somado ao encolhimento, o desemprego atingiu seu auge no primeiro trimestre de 2015 com uma taxa de $13,7 \%$, relativos a 14,176 milhões de brasileiros (PNAD, 2017). Nesse ano, os índices de inadimplência, que haviam reduzido em anos anteriores, sofreram um aumento de registro na variação, estimandose um total de 60 milhões de devedores segundo o Serviço de Proteção ao Crédito (SPC) e a Confederação Nacional de Dirigentes Lojistas (CNDL) (SPC; CNDL, 2015).

Em muitas famílias brasileiras, o impacto das crises encorajou a população a repensar seu padrão de vida na tentativa de se manter. De acordo com uma pesquisa feita pela Confederação Nacional da Indústria (CNI, 2016), em todas as faixas de renda, as estratégias mais utilizadas foram fazer uso de meios públicos, como transporte, saúde e educação, e reduzir o nível de consumo, comprando produtos mais baratos e em liquidações, enquanto que em rendas menores ocorreram medidas extremas, como mudar de casa ou vender mobílias para pagar dívidas.

Em momentos como esses, fica claro que o brasileiro é pouco estimulado a possuir uma economia para emergências ou a poupar com um fim de investimento, e sim a gastar em liquidações ou utilizar-se de créditos e parcelamentos. Sendo a família a principal fonte de conhecimento financeiro do jovem, a forma como os pais lidam com 
as finanças é repassado para os filhos que administrarão o seu próprio dinheiro no futuro.

Diante do contexto explorado, surge a seguinte questão de pesquisa: qual a influência dos fatores demográficos e socioeconômicos na atitude e comportamento financeiro de estudantes do ensino médio? Assim, o objetivo dessa pesquisa consiste em analisar a influência dos fatores demográficos e socioeconômicos na atitude e comportamento financeiro de estudantes do ensino médio nas regiões do interior de Mato Grosso do Sul e São Paulo, locais que, até então, não havia estudos desta natureza.

A pesquisa é relevante pois, para Wisniewski (2011), os problemas financeiros das famílias afetam negativamente o desenvolvimento da economia de um país em longo prazo. Tais problemas podem ser evitados com educação financeira básica.

\section{FUNDAMENTAÇÃO TEÓRICA}

\section{Relevância}

O estudo da educação financeira se tornou essencial para a economia de diversos países, majoritariamente, os de primeiro mundo como Canadá, Alemanha, Reino Unido e Estados Unidos (S\&P GLOBAL FINLIT SURVEY, 2015). Isto acontece especialmente pelo fato de que a educação financeira pode ser considerada uma ferramenta de prevenção, permitindo que os indivíduos tenham condições de entender problemas financeiros e gerenciar suas finanças pessoais de forma satisfatória, evitando o endividamento (ANDERLONI; VANDONE, 2010) e planejando melhor seu consumo (SILVA; LEAL; ARAÚJO, 2018).

Hissa (2009) ressalta que a saúde financeira possui um impacto direto na qualidade de vida, na qual o endividamento pode ser a causa de baixa produtividade, estresse, insônia, depressão e outros distúrbios sociais. Logo, "a melhoria da educação financeira propicia aos cidadãos uma melhor proteção contra infortúnios, pois ficam em uma melhor posição para se protegerem" (ARAÚJO; SOUZA, 2012, p. 19). Ademais, "a falta de controle financeiro e o endividamento das famílias em decorrência dos padrões elevados de consumo, afeta não só a saúde financeira pessoal, mas o desenvolvimento das economias e sua sustentabilidade no longo prazo" (WISNIEWSKI, 2011, p. 160).

Denegri et al. (1999) asseveram que seria interessante se a educação financeira tivesse sua inserção na educação básica, uma vez que é nesse o período que ocorre a transmissão de valores, atitudes, informações e habilidades que levarão a condutas corretas ou hábitos negativos. Outrossim, "muitas das competências e dos conhecimentos matemático financeiro necessários para promover a educação financeira passam a ter, como principal meio de disseminação, a escola" (HOFMANN; MORO, 2013, p. 49). Ante o exposto, a escola se estabelece como apoio à esta educação iniciada pela família, responsável por instruir os jovens cotidianamente (D’AQUINO, 2008).

Segundo Gorla et al. (2016), o assunto finanças é muito pouco abordado na família e o conhecimento fornecido pelas escolas é raso, tornando-os suscetíveis ao endividamento. A mesma percepção foi notada por Sousa (2012, p. 14), que afirma "esse tema não era discutido em família e que, de fato, havia uma lacuna/carência na escola com relação ao tratamento desses assuntos". Esta ausência acaba por gerar consequências futuras, como constatado por Messias, Silva e Silva (2015) em um estudo com 50 jovens entre 20 e 25 anos. Os autores encontram que o despreparo junto 
a facilidade de crédito introduz o jovem ao endividamento precoce (MESSIAS; SILVA; SILVA, 2015).

Visto a necessidade da aplicação da educação financeira como essencial para formação de cidadãos conscientes, não apenas para o controle de finanças, mas para a manutenção de uma vivência próspera e equilibrada, o próximo tópico apresenta a sua definição.

\section{Educação financeira e alfabetização financeira}

Além de a educação financeira ser uma habilidade escassa no cotidiano do brasileiro, como mencionado anteriormente, existe também carência quanto a alfabetização financeira. Ambos os termos são equivocadamente tratados como sinônimos. Huston (2010) identificou em 71 estudos individuais que 47\% usam os termos alfabetização financeira e conhecimento financeiro como sinônimos. Robb, Babiarz e Woodyard (2012) explicam que alfabetização financeira trata da tomada de decisão eficaz com base na interpretação de uma informação financeira, enquanto educação financeira se limita ao conhecimento da informação.

Os autores Atkinson e Messy (2012, p. 14) definem alfabetização financeira como "uma combinação de consciência, conhecimento, habilidades, atitudes e comportamentos necessários para fazer decisões financeiras conscientes e atingir o bemestar financeiro individual". Similarmente, para Noctor, Stoney e Stradling (1992) a alfabetização financeira é a capacidade do indivíduo de manejar e usar o dinheiro por meio de julgamentos e decisões eficazes.

Sobre educação financeira, Teixeira et al. (2010, p. 26) definem que é "a arte de aplicar os princípios e conceitos de finanças em auxílio à tomada de decisões financeiras pessoais". Claudino, Nunes e Silva (2009, p. 2) explicam que "a educação financeira compreende a inteligência de ler e interpretar números e assim transformá-los em informação para elaborar um planejamento financeiro que garanta um consumo saudável e o futuro equilibrado nas finanças pessoais".

Costa (2018, p. 26) sintetiza que o objetivo da educação financeira se refere "a possibilidade de formar pessoas com consciência sobre o uso e atribuição do dinheiro e seus gastos". De forma complementar, Faveri, Kroetz e Valentim (2012, p. 3) afirmam que a educação financeira"tem como principal objetivo informar as pessoas sobre os conceitos e produtos financeiros de forma que possam gerir suas receitas de forma consciente, diminuindo riscos e aproveitando oportunidades de poupança e investimentos que possam surgir".

Portanto, alfabetização financeira trata da fusão de habilidades que possibilitam a aplicação da educação financeira ativamente no cotidiano, já a educação financeira se refere ao conhecimento que se tem na administração dos recursos.

\section{Estudos correlatos}

No meio acadêmico não há um consenso quanto aos fatores que determinam ou podem determinar a educação financeira de um indivíduo. Todavia, frequentemente autores utilizam-se de fatores semelhantes como renda, escolaridade, idade, família e gênero.

No que tange à influência familiar, Sales (2018) notou que cerca de 32\% dos 110 alunos pesquisados obtiveram a educação financeira por meio da família, na qual destaca ser a primeira introdução aos temas: poupar e investir. Similarmente, Silva (2019, p. 45) constatou que "a maioria dos jovens adotam os mesmos padrões 
financeiros semelhantes aos da família e que a família exerce grande influência na postura dos jovens em relação ao comportamento de consumo".

Quanto ao fator renda, estudos mais recentes que cruzaram os dados entre o Indicador do Analfabetismo Funcional (INAF) do Instituto Paulo Montenegro e o Indicador de Educação Financeira (INEF) da Serasa Experian (2019) indicaram que o comportamento financeiro não possui relação proporcional à renda, visto que "o comportamento financeiro dos brasileiros com renda acima de cinco salários mínimos não é melhor do que os dos demais brasileiros". Na verdade, a experiência prática ao lidar com situações do cotidiano mostrou possuir um maior peso em relação as finanças pessoais e que o nível de letramento se mostrou irrelevante.

Potrich, Vieira e Ceretta (2013), em seu estudo, verificaram se os estudantes universitários são alfabetizados financeiramente e se a alfabetização é afetada por variáveis socioeconômicas e demográficas. Aplicou-se questionários para 534 estudantes de graduação de universidades do Rio Grande do Sul. Os achados da pesquisa apontam que os estudantes apresentam um comportamento financeiro positivo, mas não satisfatório. Ainda foi possível identificar que a alfabetização financeira é influenciada positivamente pelas variáveis: formação, ocupação, gênero e renda.

Já Potrich, Vieira e Kirch (2015) foram além, tiveram o objetivo de desenvolver um modelo que explique o nível de alfabetização financeira dos indivíduos a partir de variáveis socioeconômicas e demográficas, com amostra de 1400 respondentes do Rio Grande do Sul. Utilizaram como indicador do nível de alfabetização financeira as variáveis: atitude financeira, comportamento financeiro e conhecimento financeiro. Foram estimados modelos logit e probit com as seguintes variáveis explicativas: gênero, estado civil, dependentes, ocupação, idade, escolaridade, escolaridade do pai, escolaridade da mãe, renda própria e renda familiar. Os achados indicaram que o gênero masculino que não possue dependentes, que possui maior nível de escolaridade e que possue fontes de renda própria, apresenta maior nível de alfabetização financeira. Também constataram que a maioria dos pesquisados $(67,1 \%)$ foram classificados com baixo nível de alfabetização financeira.

Potrich (2014), por sua vez, constatou que a idade não é um fator com diferença significativa em nenhum aspecto do conhecimento financeiro (básico, avançado e total) nos grupos analisados na sua pesquisa com 1.576 habitantes das 7 mesorregiões do Rio Grande do Sul, que possuíam entre 18 e 30 anos.

Em uma pesquisa com estudantes de graduação de universidades públicas e privadas do estado do Rio Grande do Sul, Vieira et al. (2016) evidenciaram que apesar do gênero não possuir relevância no aspecto de gestão financeira, há notoriedade nos aspectos: consumo, poupança e crédito. Os dados indicam que os homens se mostraram mais conscientes em poupar dinheiro, na responsabilidade do uso do crédito e nas compras por impulso. Divergindo deste estudo, a pesquisa de Nascimento et al. (2017), cuja amostra era composta em sua maioria por mulheres, demonstrou que elas possuíam educação financeira ao criarem um planejamento das próprias finanças e possuíam também controle financeiro.

\section{PROCEDIMENTOS METODOLÓGICOS}

A presente pesquisa possui característica descritiva. Segundo Michel (2009, p. 44) "a pesquisa descritiva se propõe a verificar e explicar problemas, fatos ou 
fenômenos da vida real, com a precisão possível, observando e fazendo relações, conexões, à luz da influência que o ambiente exerce sobre eles".

A abordagem foi feita de forma quantitativa por meio de um levantamento. Santos e Parra Filho (2011, p.11) afirmam que "a quantificação dos resultados do trabalho de pesquisa é um instrumento de grande importância na constatação dos resultados".

A coleta de dados foi feita por meio da aplicação presencial de um questionário com questões fechadas adaptado do instrumento de coleta de dados de Potrich, Vieira e Kirch (2015) e do questionário de Potrich, Vieira e Ceretta (2013) em visitas nas escolas. A variável atitude financeira tem como base a escala da OECD (2013), com dez questões do tipo Likert de cinco pontos, que aponta como uma pessoa avalia sua gestão financeira. Já a variável comportamento financeiro os autores do instrumento utilizaram as escalas de Shockey (2002), O’Neill e Xiao (2012) e pela OECD (2013), com o objetivo de avaliar o comportamento financeira dos indivíduos, em 27 questões do tipo Likert de cinco pontos.

A amostra da pesquisa foi composta por 427 alunos matriculados no último ano do ensino médio de instituições públicas de cidades do interior dos estados de Mato Grosso do Sul e São Paulo no ano de 2019. A escolha dos estados foi pela proximidade das cidades investigadas, em que os pesquisadores foram pessoalmente nas instituições coletar os dados. Vale ressaltar que apenas os alunos presentes no dia da coleta responderam à pesquisa.

Os questionários foram organizados em planilhas de Excel para posteriormente serem filtrados em dados e tratados utilizando o software @Stata com as técnicas ladder e glander para todas as variáveis investigadas. O comando ladder foi utilizado com a finalidade de realizar várias transformações e testar a normalidade das distribuições após as referidas transformações. Já o comando glander foi utilizado para gerar os histogramas com as variáveis já transformadas.

Inicialmente, como análise descritiva dos dados, utilizou-se como método os testes de diferença de médias a fim de conhecer melhor as variáveis estudadas. Na sequência, na análise da influência do gênero na atitude e comportamento financeiro, aplicou-se o Teste $\mathrm{t}$ de Student com o propósito de testar se duas amostras independentes foram retiradas de populações com médias iguais. Esse teste consiste em um tipo de método paramétrico que verifica suposições acerca do parâmetro populacional, chamado média, quando há normalidade dos dados analisados (MAROCO, 2014. Por fim, na análise da influência da renda familiar e dos pais na atitude e comportamento financeiro, utilizou-se o Teste de análise de variância ANOVA, que tem como objetivo determinar se as médias de três ou mais grupos são diferentes (MAROCO, 2014).

\section{RESULTADOS E DISCUSSÃO}

$\mathrm{Na}$ primeira parte da análise foram abordados os dados do perfil dos respondentes. Conforme Tabela 1 , a maioria são estudantes do sexo feminino $(54,1 \%)$ entre 15 a 17 anos (66,5\%) e pertencentes ao estado de São Paulo (54,6\%).

Quando questionados quanto a intenção de ingressar no ensino superior, apenas uma quantidade mínima de estudantes não possui intenção $(14,1 \%)$. Verificando o contexto familiar no qual os estudantes estão inseridos, para a maioria, a renda familiar é de dois a quatro salários-mínimos $(31,4 \%)$. De acordo com os resultados apresentados 
na Tabela 1, ao observar que a maioria dos respondentes tem renda familiar de até quatro salários-mínimos e muitos têm a intenção fazer um curso superior, ter uma boa gestão dos recursos financeiros será primordial para alcançar os objetivos pretendidos e honrar com as dívidas. Ao ingressa em curso superior, independente se for instituição pública ou privada, o acadêmico terá pelo menos gastos com material, alimentação e deslocamento.

Tabela 1. Relação de perfil dos estudantes

\begin{tabular}{lcccc}
\hline & Frequência & \% & \% válida & \% acumulativa \\
\hline Idade & & & & \\
\hline De 15 a 17 anos & 284 & 66,5 & 66,5 & 66,5 \\
De 18 a 20 anos & 106 & 24,8 & 24,8 & 91,3 \\
Mais de 20 anos & 37 & 8,7 & 8,7 & 100 \\
Total & $\mathbf{4 2 7}$ & $\mathbf{1 0 0}$ & $\mathbf{1 0 0}$ & \\
\hline Sexo & & & & \\
\hline Masculino & 196 & 45,9 & 45,9 & 45,9 \\
Feminino & 231 & 54,1 & 54,1 & 100 \\
Total & $\mathbf{4 2 7}$ & $\mathbf{1 0 0}$ & $\mathbf{1 0 0}$ & \\
\hline Estado & & & & \\
\hline SP & 233 & 54,6 & 54,6 & 54,6 \\
MS & 194 & 45,4 & 45,4 & 100 \\
Total & $\mathbf{4 2 7}$ & $\mathbf{1 0 0}$ & $\mathbf{1 0 0}$ & \\
\hline Pretende ingressar no curso superior? & & & \\
\hline Sim & 367 & 85,9 & 85,9 & 85,9 \\
Não & 60 & 14,1 & 14,1 & 100 \\
Total & $\mathbf{4 2 7}$ & $\mathbf{1 0 0}$ & $\mathbf{1 0 0}$ & \\
\hline Renda familiar & & & \\
\hline Até 1 Salário-mínimo & 55 & 12,9 & 12,9 & 12,9 \\
de 1 a 2 Salários-mínimos & 122 & 28,6 & 28,6 & 41,5 \\
de 2 a 4 Salários-mínimos & 134 & 31,4 & 31,4 & 72,8 \\
de 4 a 6 Salários-mínimos & 54 & 12,6 & 12,6 & 85,5 \\
de 6 a 8 Salários-mínimos & 28 & 6,6 & 6,6 & 92 \\
Acima de 8 Salários-mínimos & 34 & 8 & 8 & 100 \\
Total & $\mathbf{4 2 7}$ & $\mathbf{1 0 0}$ & $\mathbf{1 0 0}$ & \\
\hline
\end{tabular}

Fonte. Dados da pesquisa.

Os resultados da Tabela 2 mostram que os pais são os que mais possuem ensino superior completo $(32,3 \%)$, enquanto um percentual relevante das mães possui o ensino médio completo $(33,3 \%)$. Diante desses resultados, o fato do pai e da mãe já ter um grau de instrução maior, como o ensino superior completo, pode ser um fator que impacte em um melhor comportamento financeiro de seus filhos.

Tabela 2. Escolaridade dos pais

\begin{tabular}{|c|c|c|c|c|c|c|c|c|}
\hline & \multicolumn{4}{|c|}{ Escolaridade do pai } & \multicolumn{4}{|c|}{ Escolaridade da mãe } \\
\hline & Freq. & $\%$ & $\begin{array}{c}\% \\
\text { válida }\end{array}$ & $\begin{array}{c}\% \\
\text { acum. }\end{array}$ & Freq. & $\%$ & $\begin{array}{c}\% \\
\text { válida }\end{array}$ & $\begin{array}{c}\% \\
\text { acum. }\end{array}$ \\
\hline Superior completo & 138 & 32,3 & 32,3 & 57,1 & 101 & 23,7 & 23,7 & 23,7 \\
\hline Superior incompleto & 25 & 5,9 & 5,9 & 24,8 & 35 & 8,2 & 8,2 & 31,9 \\
\hline $\begin{array}{l}\text { Ensino médio } \\
\text { completo }\end{array}$ & 81 & 19 & 19 & 19 & 142 & 33,3 & 33,3 & 65,1 \\
\hline Ensino médio & 66 & 15,5 & 15,5 & 72,6 & 59 & 13,8 & 13,8 & 78,9 \\
\hline
\end{tabular}




\begin{tabular}{lcccc|cccc} 
incompleto & & & & & & & \\
Fundamental completo & 23 & 5,4 & 5,4 & 78 & 25 & 5,9 & 5,9 & 84,8 \\
Fundamental & 83 & 19,4 & 19,4 & 97,4 & 58 & 13,6 & 13,6 & 98,4 \\
incompleto & 11 & 2,6 & 2,6 & 100 & 7 & 1,6 & 1,6 & 100 \\
Analfabeto & $\mathbf{4 2 7}$ & $\mathbf{1 0 0}$ & $\mathbf{1 0 0}$ & & $\mathbf{4 2 7}$ & $\mathbf{1 0 0}$ & $\mathbf{1 0 0}$ & \\
Total & & $\mathbf{F o n t}$ &
\end{tabular}

Fonte. Dados da pesquisa

Mediante as questões propostas no questionário, para uma análise mais consistente e robusta, buscou-se relacionar se as características mencionadas possuem alguma influência na educação financeira destes estudantes. A Tabela 3 apresenta as médias conforme as respostas dos estudantes quanto a atitude financeira (AF) e comportamento financeiro $(\mathrm{CF})$. A AF foi medida por afirmações de grau de concordância, que variavam entre: discordo plenamente, discordo parcialmente, indiferente, concordo parcialmente e concordo plenamente. Já o CF foi avaliado pelo grau de concordância baseado em hábitos: nunca, quase, às vezes, quase sempre e sempre.

Tabela 3. Índice geral de dados

\begin{tabular}{lccccc}
\hline & \multicolumn{5}{c}{ Estatística Descritiva } \\
\hline Variáveis & N & Mínimo & Máximo & Média & Erro Desvio \\
\hline AF1 & 427 & 1 & 5 & 4,663 & 0,8099 \\
AF2 & 427 & 1 & 5 & 1,892 & 1,2074 \\
AF3 & 427 & 1 & 5 & 2,529 & 1,2895 \\
AF4 & 427 & 1 & 5 & 3,681 & 1,2012 \\
AF5 & 427 & 1 & 5 & 3,304 & 1,329 \\
AF6 & 427 & 1 & 5 & 2,902 & 1,3548 \\
AF7 & 427 & 1 & 5 & 3,923 & 1,23 \\
AF8 & 427 & 1 & 5 & 3,593 & 1,4447 \\
AF9 & 427 & 1 & 5 & 2,157 & 1,3361 \\
AF10 & 427 & 1 & 5 & 3,136 & 1,379 \\
CF11 & 427 & 1 & 5 & 2,663 & 1,3647 \\
CF12 & 427 & 1 & 5 & 3,988 & 1,0866 \\
CF13 & 427 & 1 & 5 & 3,138 & 1,3521 \\
CF14 & 427 & 1 & 5 & 2,904 & 1,3471 \\
CF15 & 427 & 1 & 5 & 2,953 & 1,3747 \\
CF16 & 427 & 1 & 5 & 3,522 & 1,2108 \\
CF17 & 427 & 1 & 5 & 3,459 & 1,0899 \\
CF18 & 427 & 1 & 5 & 2,801 & 1,452 \\
CF19 & 427 & 1 & 5 & 4,152 & 1,1659 \\
CF20 & 427 & 1 & 5 & 2,979 & 1,3864 \\
CF21 & 427 & 1 & 5 & 2,009 & 1,1867 \\
CF22 & 427 & 1 & 5 & 1,813 & 1,1435 \\
CF23 & 427 & 1 & 5 & 4,035 & 1,2786 \\
CF24 & 427 & 1 & 5 & 3,246 & 1,4801 \\
CF25 & 427 & 1 & 5 & 3,213 & 1,3786 \\
CF26 & 427 & 1 & 5 & 3,415 & 1,2961 \\
CF27 & 427 & 1 & 5 & 3,698 & 1,3251 \\
CF28 & 427 & 1 & 5 & 3,232 & 1,3908 \\
CF29 & 427 & 1 & 5 & 3,105 & 1,374 \\
CF30 & 427 & 1 & 5 & 2,258 & 1,307 \\
& & & & &
\end{tabular}




\begin{tabular}{llllcc} 
CF31 & 427 & 1 & 5 & 4,145 & 1,1858 \\
CF32 & 427 & 1 & 5 & 2,696 & 1,3378 \\
CF33 & 427 & 1 & 5 & 2,81 & 1,3248 \\
CF34 & 427 & 1 & 5 & 2,998 & 1,4233 \\
CF35 & 427 & 1 & 5 & 2,81 & 1,5211 \\
AF2I & 427 & 1 & 5 & 4,1077 & 1,20741 \\
CF32I & 427 & 1 & 5 & 3,3044 & 1,3378 \\
\hline
\end{tabular}

Fonte. Dados da pesquisa. Nota. $\mathrm{AF}=$ Alfabetização financeira; $\mathrm{CF}=$ Comportamento Financeiro

Ante as questões de atitude financeira, de acordo com a Tabela 3, quando questionados quanto ao futuro, a maioria considera importante definir metas (AF14,663) e acredita que o modo como administram o dinheiro os afetará futuramente (AF8-3,593), além de não achar mais satisfatório gastar do que poupar. Porém, ao mesmo tempo, não possuem preocupações com o futuro, apenas com o presente (AF21,892), provavelmente por ser impossível para a família poupar, conforme a média de AF3-2,529 e a dificuldade em construir um planejamento de gastos familiar (AF62,902). Há uma preocupação razoável dos entrevistados com as decisões tomadas quanto ao dinheiro (AF4-3,681), porém gastam pela sensação de bem-estar proporcionado pela compra (AF5-3,304) e concordam que o dinheiro é feito para gastar (AF10-3,136), dispondo a gastá-lo em coisas importantes para si (AF7-3,923).

Esses resultados permitem inferir que os estudantes estão cientes que precisam estabelecer metas, já que a forma como fazem a gestão dos recursos financeiros impactará nos investimentos futuros. Apesar de apontarem que estão mais preocupados com o presente do que com o futuro, o fato de terem metas estabelecidas, mesmo que de curto prazo, pode ajudá-los a ter um controle financeiro satisfatório. Pelo fato de os respondentes considerarem que é difícil poupar, é importante que eles refletam sobre criar uma reserva, mesmo que de início seja um valor considerado baixo, mas que na sequência esse valor possa ser aumentado aos poucos. Esse tipo de comportamento tende a criar uma cultura que possibilitará a pessoa a trabalhar com um planejamento de investimento de médio e longo prazo.

No que concerne o comportamento financeiro, de acordo com a Tabela 3, as médias demonstraram que o controle de gastos pessoais (CF11-2,663) se mostra escasso, sendo quase nunca feito. Da mesma forma, os estudantes quase nunca fazem um plano de gastos ou orçamento (CF14-2,904) e registros financeiros organizados (CF25-3,213) são mantidos apenas às vezes. Além de quase nunca identificarem os custos na compra de um produto no crédito (CF15-2,953), não guardar parte da renda todo mês (CF20-2,979) e não terem conseguido poupar dinheiro nos últimos 12 meses (CF33-2,81). Comportamentos relacionados com economias são feitos apenas às vezes, como reservas de dinheiro para necessidades futuras (CF13-3,138), sendo que reservas iguais ou maiores às despesas mensais quase nunca são feitas (CF30-2,258). Os entrevistados não hesitam em compras por impulso (CF26-3,415), não guardam dinheiro para atingir objetivos de longo prazo (CF28-3,232), não poupam ao receber um aumento salarial ou mesada (CF29-3,105).

Observando os objetivos, esses são traçados apenas às vezes como orientação para as decisões financeiras (CF16-3,522) e da mesma forma alcançados (CF17-3,459). Contudo, as contas são quase sempre pagas em dia (CF19-4,152), há uma análise antes de fazer uma compra grande (CF23-4,035), comparação de preços (CF12-3,988) e verificam se possuem condições de pagar ao efetuar uma compra (CF31-4,145). Além 
de nunca pedirem dinheiro emprestado para família ou amigos para pagar as contas (CF22-1,813) e quase nunca gastarem antes de obter o dinheiro (CF21-2,009).

Esses achados permitem inferir que, no comportamento financeiro, os respondentes praticamente não têm um controle efetivo dos gastos, como um orçamento. Além disso, na prática, não procuram poupar dinheiro e acabam fazendo compras por impulso. Caso a situação financeira da família não seja boa, o fato de não ter um bom orçamento e controle dos gastos, tende a agravar uma situação ruim, o que aumenta a dificuldade de encontrar alternativas para contornar o problema.

Em suma, percebe-se uma educação financeira que não pode ser considerada boa, sendo a atitude financeira razoável e o comportamento financeiro preocupante, mesmo levando em consideração questões positivas como pagamento das contas em dia, análises ao fazer uma compra grande, comparar preços e verificar a própria condição ao efetuar uma compra. Os resultados até mostram que, na atitude financeira, os respondentes têm ciência de que precisam estabelecer metas e que a forma de controle dos recursos impactará nos investimentos futuros, mesmo que apontam estar mais preocupados com o presente. Mas quanto ao comportamento financeiro, na prática, não utilizam um orçamento para estabelecer metas e controlar os gastos.

A Tabela 4 apresenta a análise da influência do gênero na atitude financeira e comportamento financeiro.

Tabela 4. Teste $\mathrm{t}$ - Gênero e Atitude Financeira/Comportamento Financeiro

\begin{tabular}{cccccccc}
\hline & $\mathbf{n}$ & $\mathbf{x}$ e $\boldsymbol{\sigma}$ Masculino & $\mathbf{n}$ & $\mathbf{x}$ e $\boldsymbol{\sigma}$ Feminino & da diferença & $\mathbf{t}(\mathbf{d f})$ & p-valor \\
\hline AF & 96 & $1,83(0,09)$ & 231 & $1,83(0,09)$ & $-0,002$ & $-0,1235(425)$ & 0,902 \\
CF & 96 & $3,19(0,04)$ & 231 & $1,83(0,04)$ & $-0,096$ & $-1,6078(425)$ & 0,108 \\
\hline
\end{tabular}

Fonte. Dados da pesquisa (2020). Nota. Significante ao nível 5\%. $\square$ representa a média e $\boldsymbol{\sigma}$ representa o desvio padrão. Foi considerado um intervalo de confiança de $95 \%$. Questionários não respondidos foram considerados como inválidos e excluídos das análises.

Assim, conforme Tabela 4, similarmente ao que foi demonstrado por Vieira et al. (2016) e contrariando Nascimento et al. (2017), estudantes do gênero masculino e feminino demonstraram as mesmas médias de escores para atitudes financeiras e comportamento financeiro. Esses resultados mostram que não há diferença significativa na análise do Teste $t$, ou seja, não é possível afirmar que o gênero influência na atitude financeira e comportamento financeiro dos respondentes desta pesquisa.

A Tabela 5 apresenta a análise da influência da renda familiar na atitude financeira e comportamento financeiro.

Tabela 5. Anova - Renda e Atitude Financeira/Comportamento Financeiro

\begin{tabular}{cccccc}
\hline & Soma dos quadrados & Grau de liberdade & Quadro Médio & F & Sig \\
\hline $\mathrm{AF}$ & 8,18 & 426 & 0,019 & 0,41 & 0,843 \\
$\mathrm{CF}$ & 161,53 & 426 & 0,379 & 1,26 & 0,279 \\
\hline
\end{tabular}

Fonte. Dados da pesquisa (2020). Nota. Significante ao nível 5\%. $\square$ representa a média e $\boldsymbol{\sigma}$ representa o desvio padrão. Foi considerado um intervalo de confiança de $95 \%$. Questionários não respondidos foram considerados como inválidos e excluídos das análises.

Com base na Tabela 5, feita a comparação entre renda e atitudes e comportamentos financeiros, não foi constatado que a renda exerce influência, o que também foi identificado nos dados do INAF do Instituto Paulo Montenegro e o INEF da Serasa Experian (2019). O presente achado permite inferir que mesmo a família tendo uma renda alta, o que pode gerar maior movimentação dos recursos com 
gastos/investimentos, a atitude financeira e comportamento financeiro tende a não ter diferença significativa diante de famílias com rendas menores.

As Tabelas 6 e 7 apresentam análises sobre as influências das escolaridades da mãe e do pai na atitude financeira e comportamento financeiro. Considerando os dados dessas Tabelascomo influências obtidas da mãe e do pai, nota-se uma diferença perceptível nas respostas dos estudantes quanto às atitudes financeiras pela variação da escolaridade de ambos. Sendo assim, os resultados encontrados refletem o que foi demonstrado por Sales (2018) e Silva (2019) em suas pesquisas, nas quais a educação financeira dos estudantes avaliados advém da família.

Os resultados das Tabelas 6 e 7 permitem inferir que o nível de escolaridade da mãe e do pai impacta na atitude financeira e comportamento financeiro do estudante de ensino médio que fez parte da presente pesquisa. Com isso, espera-se que o nível de escolaridade da mãe e do pai influencie o estudante quanto a consciência da necessidade de planejamento, de estabelecer metas, de que a forma de controle dos recursos impactará nos investimentos futuros, bem como na prática da operacionalização desses controles, como na utilização e acompanhamento do orçamento.

Tabela 6. Anova - Escolaridade Mãe e Atitude Financeira/Comportamento Financeiro

\begin{tabular}{cccccc}
\hline & Soma dos quadrados & Grau de liberdade & Quadro Médio & F & Sig \\
\hline $\mathrm{AF}$ & 8,18 & 426 & 0,019 & 2,16 & 0,046 \\
$\mathrm{CF}$ & 161,53 & 426 & 0,379 & 1,73 & $0,113^{*}$ \\
\hline
\end{tabular}

Fonte. Dados da pesquisa (2020). Nota.Significante ao nível 5\% e*10\%. Foi considerado um intervalo de confiança de $95 \%$ e $* 90 \%$. Questionários não respondidos foram considerados como inválidos e excluídos das análises.

Tabela 7. Anova - Escolaridade Pai e Atitude Financeira/Comportamento Financeiro

\begin{tabular}{cccccc}
\hline & Soma dos quadrados & Grau de liberdade & Quadro Médio & F & Sig \\
\hline $\mathrm{AF}$ & 8,18 & 426 & 0,019 & 2,37 & 0,029 \\
$\mathrm{CF}$ & 161,53 & 426 & 0,379 & 1,7 & $0,119^{*}$ \\
\hline
\end{tabular}

Fonte. Dados da pesquisa (2020). Nota.Significante ao nível 5\% e *10\%. Foi considerado um intervalo de confiança de $95 \%$ e $* 90 \%$. Questionários não respondidos foram considerados como inválidos e excluídos das análises.

Na sequência, a Tabela 8 apresenta a análise da influência da idade dos estudantes de ensino médio na atitude financeira e comportamento financeiro.

Tabela 8. Anova - Idade e Atitude Financeira/Comportamento Financeiro

\begin{tabular}{cccccc}
\hline & Soma dos quadrados & Grau de liberdade & Quadro Médio & F & Sig \\
\hline $\mathrm{AF}$ & 8,18 & 426 & 0,019 & 0,04 & 0,965 \\
$\mathrm{CF}$ & 161,53 & 426 & 0,379 & 2,73 & $0,067^{*}$ \\
\hline
\end{tabular}

Fonte. Dados da pesquisa (2020). Nota.Significante ao nível 5\% e *10\%. Foi considerado um intervalo de confiança de $95 \%$ e $* 90 \%$. Questionários não respondidos foram considerados como inválidos e excluídos das análises.

Com base na Tabela 8 , nota-se que conforme a idade do estudante, o comportamento financeiro tende a variar. Tal achado contradiz Potrich (2014) ao demonstrar que a idade possui, de certa forma, influência no comportamento financeiro do estudante da amostra. De acordo com os resultados, mesmo não sendo constatado diferença estatística significativa entre os respondentes na atitude financeira, na análise do comportamento financeiro, ao nível de $10 \%$, pode-se inferir que a idade influência 
no comportamento financeiro entre os estudantes. Vale ressaltar que a idade afeta o comportamento financeiro dos estudantes, mesmo a maioria tendo idade entre 15 e 17 anos e poucos acima de 20 anos.

Em suma, os estudantes demonstram uma atitude financeira razoável e um conhecimento financeiro insatisfatório. Ainda que haja consciência da importância de metas e a administração do dinheiro para o futuro, tal pensamento não é refletido no comportamento. Os resultados demonstram que gênero e renda não exercem influência na educação financeira dos estudantes, mas o grau de instrução dos pais interfere.

\section{CONSIDERAÇÕES FINAIS}

Esta pesquisa buscou verificar a influência dos fatores demográficos e socioeconômicos na atitude e comportamento financeiro de estudantes que estavam cursando o terceiro ano do ensino médio. Para tal, foram utilizados questionários adaptados de Potrich, Vieira e Kirch (2015) e Potrich, Vieira e Ceretta (2013). Assim, foi possível identificar que a educação financeira se encontra escassa no cotidiano destes estudantes, sendo a atitude financeira mínima e o comportamento financeiro insuficiente. Os fatores demográficos e socioeconômicos analisados demostram que gênero e renda não exercem influência sobre a educação financeira do estudante da amostra.

Os achados do presente estudo mostram que os estudantes pesquisados até concordam que é preciso estabelecer metas diante dos recursos que detém e que isso afetará seus planos futuros, porém, revelam estar mais preocupados com o presente do que com o futuro e, ainda, a maioria afirma que tem dificuldade para poupar dinheiro. Apesar da maioria evidenciar que é preciso ter metas e que essas decisões impactam no futuro, os estudantes não utilizam um orçamento para planejamento e controle dos recursos. Esses resultados são preocupantes, pois além de não terem um controle efetivo dos recursos e gastos realizados, uma situação de dificuldade financeira tende a ser agravada quando compras são feitas por impulso, o que foi constatado na maioria dos respondentes.

$\mathrm{Na}$ análise da influência dos fatores demográficos e socioeconômicos na atitude e comportamento financeiro de estudantes pesquisados, os resultados do estudo permitem afirmar que o nível de escolaridade da mãe e do pai impactam na atitude e comportamento financeiro do estudante. Diante desse achado, famílias com maior nível de formação, tendem a possuir mais informação e conhecimento, o que afetará a atitude e comportamento financeiro dos filhos no papel de estudantes.

Um outro achado relevante é quanto a influência da idade na atitude e comportamento financeiro. Os resultados apontam que apesar da maioria dos estudantes terem idades entre 15 e 17 anos e a minoria acima de 20 anos, a idade influência no comportamento financeiro entre os estudantes analisados. Para se ter um nível desejado de atitude e comportamento financeiro, a escola pode ser determinante, com maior investimento no desenvolvimento de atividades nas disciplinas e projetos complementares, contemplando discussões teóricas e dinâmicas com situações próximas da realidade dos estudantes.

A contribuição aos municípios e escolas estudadas evidencia-se no esclarecimento dos fatores que influenciam os estudantes em suas decisões financeiras. Logo, pode então servir como justificativa para a criação de iniciativas para a propagação da educação financeira para que os jovens brasileiros venham a se tornar 
adultos prudentes em relação as suas economias, tornando-se a base para que possam administrar suas finanças na vida adulta (D’AQUINO, 2009). Com esta pesquisa, possibilitou-se ampliar o estudo para identificar a educação financeira na região do interior do estado de São Paulo e Mato Grosso do Sul, onde, até então, não havia estudos desta natureza.

As cidades cujos alunos foram pesquisados apresentam características semelhantes, são próximas, fazem parte da região de divisa entre os estados de São Paulo e Mato Grosso do Sul. A região tem apresentado um ritmo acelerado de crescimento econômico e, como consequência, demográfico, influenciado por investimentos industriais. Influenciado também por incentivos fiscais, grandes empresas foram construídas, o que afetou na instalação de empresas de porte médio e aqueceu o mercado das pequenas empresas, como às diversas necessidades da população em crescimento, como investimento em saneamento, saúde, educação e infraestrutura. Em região que estão em processo de evolução, investir em educação financeira torna-se essencial, tendo em vista que as famílias podem ter um controle mais consistente dos recursos disponíveis.

As limitações durante a execução deste trabalho ocorreram pela falta de acesso aos estudantes do ensino médio de escolas particulares. Além de que a quantidade de estudantes nas escolas particulares mostrou-se ser consideravelmente inferior quando comparado com a quantidade de alunos nas escolas públicas. O estudo também se limita as regiões analisadas, cidades que fazem parte da divisa entre os estados de São Paulo e Mato Grosso do Sul.

Sugere-se que em futuras pesquisas seja realizado um comparativo entre escolas públicas e particulares com o objetivo de evidenciar os fatores sociodemográficos presentes em cada ambiente e influenciáveis na educação financeira, servindo também com o propósito de apontar possíveis desigualdades sociais presentes.

\section{REFERÊNCIAS}

ANDERLONI, L.; VANDONE, D. Risk of overindebtedeness and behavioral factors. In: LUCARELLI, C.; BRIGHETTI, G. (ed.). Risk tolerance in financial decision making. London: Palgrave Macmillan, 2010.

ARAÚJO, F.; SOUZA, M. Educação financeira para um Brasil sustentável: evidências da necessidade da atuação do Banco Central do Brasil em educação financeira para o cumprimento de sua missão. Trabalho para Discussão do Banco Central do Brasil, n. 280. Brasília, 2012.

ATKINSON, A.; MESSY, F. Measuring financial literacy: results of the OECD/International Network on Financial Education (INFE) Pilot Study. OECD Working Papers on Finance, Insurance and Private Pensions, n. 15, p. 1-75, 2012.

CARVALHO, L.; SCHOLZ, R. 'Se vê o básico do básico, quando a turma rende': cenário da educação financeira no cotidiano escolar. Revista Brasileira de Gestão e Inovação, v. 6, n. 2, p. 102-125, 2018. 
CLAUDINO, L.; NUNES, M.; SILVA, F. Finanças pessoais: um estudo de caso com servidores públicos. In: SEMINÁRIOS EM ADMINISTRAÇÃO, 12., 2009, São Paulo. Anais [...]. São Paulo: SEMEAD, 2009.

CONFEDERAÇÃO NACIONAL DA INDÚSTRIA. Retratos da sociedade brasileira: dois anos de crise econômica. Indicadores CNI, ano 5, n. 34, p. 1-12, 2016.

CONFEDERAÇÃO NACIONAL DO COMÉRCIO DE BENS, SERVIÇOS E TURISMO. Número de brasileiros endividados. CNC. Brasília, 2020. Disponível em: http://cnc.org.br/editorias/economia/noticias/em-meio-pandemia-numero-de-brasileirosendividados-cai-mesmo-com. Acesso em: 7 out. 2020.

COSTA, M. Educação financeira na escola do campo: a importância de jogos matemáticos em sua aprendizagem. 2018. Monografia (Graduação em Pedagogia) Universidade Federal da Paraíba, João Pessoa, 2018.

COSTA, F.; LARN, J. A. A compra por impulso em ambientes on-line. Rev. adm. empres., v. 43, n. 4, p. 36-47, 2003.

D’AQUINO, C. E o que é a educação financeira? Educação Financeira. São Paulo, 2009. Disponível em:

http://educacaofinanceira.com.br/index.php/escolas/conteudo/513. 2009. Acesso em: 28 ago. 2019.

D’AQUINO, C. Educação financeira: como educar seus filhos. Rio de Janeiro: Elsevier, 2008.

DENEGRI, M.; PALAVECINOS, M.; RIPOLL, M.; YÁÑEZ, V. Caracterización psicológica del consumidor de la IX Región. In: DENEGRI, M.; FERNÁNDEZ, F.; ITURRA, R.; PALAVECINOS, M.; RIPOLL, M. (eds.). Consumir para vivir y no vivir para consumir. Temuco, Chile: Ediciones Universidad de La Frontera, 1999.

FAVERI, D. B.; KROETZ, M.; VALENTIM, I. Educação financeira para crianças. In: SIMPÓSIO DE EXCELÊNCIA EM GESTÃO E TECNOLOGIA, 9., 2012, Resende. Anais [...]. Resende: SEGeT, 2012.

GORLA, M.; MAGRO, C.; SILVA, T.; NAKAMURA, W. A educação financeira dos estudantes do ensino médio de rede pública segundo aspectos individuais, demográficos e de socialização. In: CONGRESSO USP DE CONTROLADORIA E

CONTABILIDADE, 16., 2016, São Paulo. Anais [...]. São Paulo: FEA-USP, 2016.

HISSA, G. Cartilha de finanças pessoais. Boa Vista: Editora Boa Vista, 2009.

HOFMANN, R. M.; MORO, M. L. F. Educação matemática e educação financeira: perspectivas para a ENEF. Zetetiké, v. 20, n. 38, p. 37- 54, 2013.

HUSTON, S. J. Measuring financial literacy. Journal of Consumer Affairs, v. 44, n. 2 , p. 296-316, 2010. 
MAROCO, J. Análise estatística com utilização do SPSS. 6. ed. Lisboa: ReportNumber, 2014.

MESSIAS, J. F.; SILVA, J. U.; SILVA, P. H. C. Marketing, crédito \& consumismo: impactos sobre o endividamento precoce dos jovens brasileiros. Revista Eniac Pesquisa, v. 4, n. 1, p. 43-59, 2015.

MICHEL, M. H. Metodologia e pesquisa científica em ciências sociais. 2. ed. São Paulo. Atlas, 2009.

NASCIMENTO, B.; CASTRO, J.; COSTA, M.; FONSÊCA, F. Comportamento financeiro do consumidor: educação financeira de alunos de ensino médio em escolas públicas e privadas. Revista Pesquisa Em Administração UFP, v. 1, n. 1, p. 22-39, 2017.

NOCTOR, M.; STONEY, S.; STRADLING, R. Financial literacy. London: National Foundation for Educational Research, 1992.

OLIVEIRA, A.; MACHADO, F.; MARTINS, J.; SPOSITO, R. A importância da educação financeira no contexto escolar e familiar: uma amostra do projeto implantado na UNESPAR. Universidade Estadual do Paraná, Apucarana, 2016.

PESQUISA NACIONAL POR AMOSTRA DE DOMICÍLIOS. Indicadores IBGE: pesquisa nacional por amostra de domicílios contínua. PNAD contínua trimestral. Rio de Janeiro: IBGE - Coordenação de Trabalho e Rendimento, 2017.

POTRICH, A. Alfabetização financeira: integrando conhecimento, atitude e comportamento financeiros. 2014. Dissertação (Mestrado em Administração) Programa de Pós-Graduação em Administração, Universidade Federal de Santa Maria, Santa Maria, 2014. Disponível em: http://repositorio.ufsm.br/handle/1/4672. Acesso em: 6 out. 2020 .

POTRICH, A. C. G.; VIEIRA, K. M.; CERETTA, P. S. Nível de alfabetização financeira dos estudantes universitários: afinal, o que é relevante? RECADM - Revista Eletrônica de Ciência Administrativa, v. 12, n. 3, p. 1-20, 2013.

POTRICH, A.; VIEIRA, K. M.; KIRCH, G. Determinantes da alfabetização financeira: análise da influência de variáveis socioeconômicas e demográficas. Rev. cont, finance., v. 26, n. 69, p. 362-377, 2015. Disponível em:

http://www.scielo.br/scielo.php?scrip=sci_arttext\&pid=S1519-

$70772015000300362 \& I n g=p t \& n r m=$ iso. Acesso em: 17 jan. 2020.

ROBB, C. A.; BABIARZ, P.; WOODYARD, A. The demand for financial professionals' advice: the role of financial knowledge, satisfaction, and confidence.

Financial Services Review, v. 21, n. 4, p. 291-305, 2012. 
S\&P GLOBAL FINLIT SURVEY. Financial literacy around the world: insights from the S\&P Global FinLit Survey. Washington: GEFLEC, 2015. Disponível em: https://gflec.org/initiatives/sp-global-finlit-survey/. Acesso em: 5 out. 2019.

SALES, V. A educação financeira no contexto do aprendizado escolar: um estudo com alunos do ensino fundamental II em uma escola particular no interior de Pernambuco. 2018. Monografia (Graduação em Ciências Contábeis) - Universidade Federal da Paraíba, João Pessoa, 2018.

SANTOS, J. A.; PARRA FILHO, D. Metodologia científica. 2. ed. São Paulo: Cengage Learning, 2011.

SERASA EXPERIAN. Educação financeira do brasileiro vai além da escolaridade, revela estudo inédito da Serasa Experian e do IBOPE Inteligência. Serasa Experian. São Paulo, 2019. Disponível em: https://www.serasaexperian.com.br/sala-deimprensa/educacao-financeira-do-brasileiro-vai-alem-da-escolaridade-revela-estudoinedito-da-serasa-experian-e-do-ibope-inteligencia. Acesso em: 14 ago. 2019.

SERVIÇO DE PROTEÇÃO AO CRÉDITO; CONFEDERAÇÃO NACIONAL DE DIRIGENTES LOJISTAS. Indicadores econômicos SPC Brasil e CNDL. Brasília: SPC e CNDL, 2015.

SILVA, L. Análise da abordagem e relevância da educação financeira no contexto do ensino médio em escola privada no município de Natal-RN. 2019. Trabalho de Conclusão de Curso (Graduação em Administração) - Curso de Administração, Universidade Federal do Rio Grande do Norte, Natal, 2019.

SILVA, M. A.; LEAL, E. A.; ARAUJO, T. S. Habilidades matemáticas e o conhecimento financeiro no ensino médio. Revista de Contabilidade e Organizações, v. 12, e147269, 2018. Disponível em:

https://doi.org/10.11606/issn.1982-6486.rco.2018.147269. Acesso em: 7 out. 2020.

SOUSA, L. Resolução de problemas e simulações: investigando potencialidades e limites de uma proposta de educação financeira para alunos do ensino médio de uma escola da rede privada de Belo Horizonte (MG). 2012. Dissertação (Mestrado em Educação Matemática) - Mestrado Profissional em Educação Matemática, Universidade Federal de Ouro Preto, Ouro Preto, 2012.

TEIXEIRA, A.; WUNDERLICH, A.; SANTOS, F.; FERREIRA, R. Vantagens e desvantagens da implantação da disciplina educação financeira nas escolas de ensino médio na cidade de pinhais. 2010. Trabalho de Conclusão de Curso (Graduação em Administração de Empresas) - Faculdades de Pinhais, Pinhais, 2010.

VIEIRA, K.; KUNKEL, F.; CAMPARA, J.; PARABONI, A. Alfabetização financeira dos jovens universitários Rio-Grandenses. Desenvolve Revista de Gestão do

Unilasalle, v. 5, n. 1, p. 107-133, 2016. 
VIEIRA, S.; BATAGLIA, R.; SEREIA, V. Educação financeira e decisões de consumo, investimento e poupança: uma análise dos alunos de uma universidade pública do norte do Paraná. Revista de Administração da UNIMEP, v. 9, n. 3, p. 61-86, 2011.

WISNIEWSKI, M. L. G. A importância da educação financeira na gestão das finanças pessoais: uma ênfase na popularização do mercado de capitais brasileiro. Revista intersaberes, v. 6, n. 11, p. 155-170, 2011.

O presente trabalho foi realizado com apoio da Fundação Universidade Federal de Mato Grosso do Sul - UFMS/MEC - Brasil 